\title{
Prostaglandin synthetase activity in acute ulcerative colitis: effects of treatment with sulphasalazine, codeine phosphate and prednisolone
}

\author{
P. R. SMITH, D. J. DAWSON, AND C. H. J. SWAN \\ From the Department of Gastroenterology and Medical Research Laboratories, \\ North Staffordshire Hospitals Centre, Stoke-on-Trent
}

SUMmARY Prostaglandin synthetase activity in rectal biopsy specimens from patients with ulcerative colitis has been shown to fall on treatment with sulphasalazine, local steroids, and codeine phosphate. In vitro studies have shown that sulphasalazine is an inhibitor of prostaglandin synthetase, although less potent than indomethacin, whereas prednisolone and codeine phosphate were inactive. It is suggested that the therapeutic action of sulphasalazine may be related in part to its action in inhibiting prostaglandin biosynthesis.

It is well known that administered prostaglandins (PGs) can cause diarrhoea (Horton et al., 1968; Misiewicz et al., 1969; Cummings et al., 1972) and endogenous prostaglandins have been implicated in the pathogenesis of diarrhoea in several pathological states (Sandler et al., 1968; Williams et al., 1968). The role of prostaglandins in the pathophysiology of ulcerative colitis where diarrhoea is a significant symptom is uncertain. However, it has been shown that faeces from patients with active ulcerative colitis contain higher levels of PG-like material than faeces from controls (Gould, 1975) and that rectal biopsy specimens from ulcerative colitis have high prostaglandin synthetase activity (Harris et al., 1978a). Peripheral venous blood from ulcerative colitics contains higher levels of PG-like material than controls (Harris et al., 1978b) and, in addition, excretion of the main urinary metabolite of $\mathrm{PGF}_{2} \alpha$ is raised (Gould et al., 1977).

In an attempt to determine the relationship between disease activities and prostaglandin production we have assayed prostaglandin synthetase in rectal biopsy material in a group of ulcerative colitics. We have extended the investigation to examine, in vitro, the effects of colonic prostaglandin biosynthesis of therapeutic agents used in the treatment of these patients.

Received for publication 29 March 1979

\section{Methods}

SERIAL STUDY OF PG SYNTHETASE ACTIVITY Rectal biopsies (20-120 mg wet weight) were obtained from a group of seven patients diagnosed clinically and radiologically as having ulcerative colitis. Each patient had active disease confirmed sigmoidoscopically, with typical histological appearances of crypt abscesses and round cell infiltration. Biopsies were taken at diagnosis and after two and four weeks treatment with sulphasalazine (Salazopyrin, Pharmacia) $1 \mathrm{~g}$ tds, codeine phosphate BP (60-240 mg daily), and daily prednisolone enemata (Predsol, Glaxo Laboratories Ltd.). Prostaglandin synthetase activities were measured by a radiometric method previously described (Harris et al., 1978a).

EFFECT ON PG SYNTHETASE OF DRUGS USED IN THE TREATMENT OF ULCERATIVE COLITIS

Human colonic mucosa was used as a source of prostaglandin synthetase. Inflamed colon was obtained at surgery from an acute ulcerative colitic undergoing panproctocolectomy, and uninvolved colon was taken for comparison from a patient undergoing colectomy for polyposis coli. The specimens were transported in ice/acetone mixture and stored at $-70^{\circ} \mathrm{C}$. Homogenates of mucosal scrapings from each colon were assayed for prostaglandin 802 


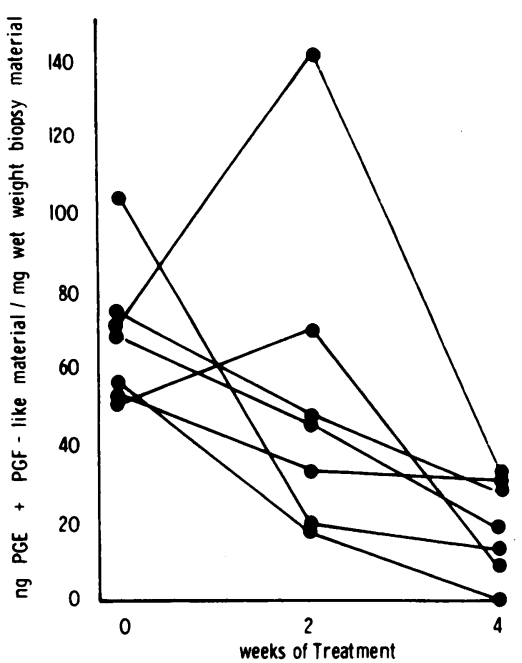

Fig. 1 Prostaglandin synthetase activities in rectal biopsy material from ulcerative colitics upon diagnosis and at subsequent two weekly intervals after starting treatment with sulphasalazine, prednisolone, and codeine phosphate.

synthetase activity in the presence of either sulphasalazine, codeine phosphate, prednisolone, or indomethacin at concentrations 10 to $1250 \mu \mathrm{mol} / \mathrm{l}$.

The presence of specific prostaglandins was confirmed by thin layer chromatography (TLC) against authentic prostaglandin standards using the AII solvent system of Green and Samuelsson (1964).

\section{Results}

\section{SERIAL STUDY OF PG SYNTHETASE} ACTIVITIES

The prostaglandin synthetase activities in the group of patients at 0,2 , and 4 weeks treatment are shown in Fig. 1. Activities are expressed as total PG production per $\mathrm{mg}$ wet weight tissue. In the assay system approximately $95 \%$ of prostaglandins produced were of $\mathrm{E}$ and $\mathrm{F}$ types (as determined by thin layer chromatography, $\mathrm{Rf}$ values: authentic $\mathrm{PGE}_{2}$, 0.71 ; authentic $\mathrm{PGF}_{2} \alpha, 0.50$; reaction products, $0.72 ; 0.51)$. While there is no significant difference between mean activities at diagnosis and after two weeks' treatment $(P=0.48)$, the decline in mean activity between 0 and four weeks' treatment is highly significant $(\mathrm{P}=0.001$, Student's $t$ test $)$.

EFFECT ON PG SYNTHETASE OF DRUGS USED IN TREATMENT OF ULCERATIVE COLITIS Prostaglandin synthetase activities measured in mucosal homogenates incubated without drugs were:
Normal mucosa:

$24 \cdot 5 \pm 4 \cdot 35 \mathrm{ng}$. PG-like material formed $/ \mathrm{mg}$ wet weight tissue

Colitic mucosa:

$76 \cdot 1 \pm 8 \cdot 32$ ng. PG-like material formed $/ \mathrm{mg}$ wet weight tissue

each value being the mean of 16 determinations \pm 1 SEM.

The percentage inhibition of prostaglandin biosynthesis produced by sulphasalazine and by indomethacin is shown in Fig. 2, each value being the mean of four experiments. Prostaglandin production was inhibited by sulphasalazine in both normal and colitic mucosae to a similar extent. By comparison, indomethacin was, at lower concentrations, a more potent inhibitor of prostaglandin biosynthesis in both colons (IC50 sulphasalazine in normal colon $251 \mu \mathrm{mol} / 1$; IC50 indomethacin in normal colon, $18 \cdot 2 \mu \mathrm{mol} / \mathrm{l})$. Higher concentrations of indomethacin $(100-500 \mu \mathrm{mol} / \mathrm{l})$ were less inhibitory to prostaglandin biosynthesis in the normal human colon.

Incubation of homogenates with prednisolone or codeine phosphate resulted in little or no inhibition $(<5 \%)$ of prostaglandin production over the range of concentrations tested (Fig. 2).

\section{Discussion}

Our results show that prostaglandin synthetase activity in the mucosa of ulcerative colitics with active disease falls when patients are treated with sulphasalazine, prednisolone enemata, and codeine phosphate. The fall in prostaglandin synthetase activity in the rectal biopsy specimens prompted investigations to determine whether any of the therapeutic agents inhibited prostaglandin biosynthesis in colonic mucosa. Waller (1973) suggested that sulphasalazine might be effective as a prostaglandin synthetase inhibitor, and certainly sulphasalazine has been shown to inhibit the resting tone of the isolated rat fundic strip preparation, thought to be maintained by production of endogenous prostaglandins (Gould, 1975; Collier et al., 1976a). Our results demonstrate that sulphasalazine is a relatively potent inhibitor of prostaglandin biosynthesis in mucosal homogenates of colon affected by ulcerative colitis.

Sulphasalazine is known to reach levels of $50 \mu \mathrm{mol} / 1$ in serum of peripheral venous blood when administered orally in a dose of 3-6 g/day (Das et al., 1973). Although intracolonic concentrations are difficult to measure, one would expect them to be at least as high and possibly higher than peripheral venous concentration. The inhibition of prostaglandin synthesis by sulphasalazine at a concentration of $100-300 \mu \mathrm{mol} / 1$ obtained in this study may there- 
(a) SULPHASALAZINE

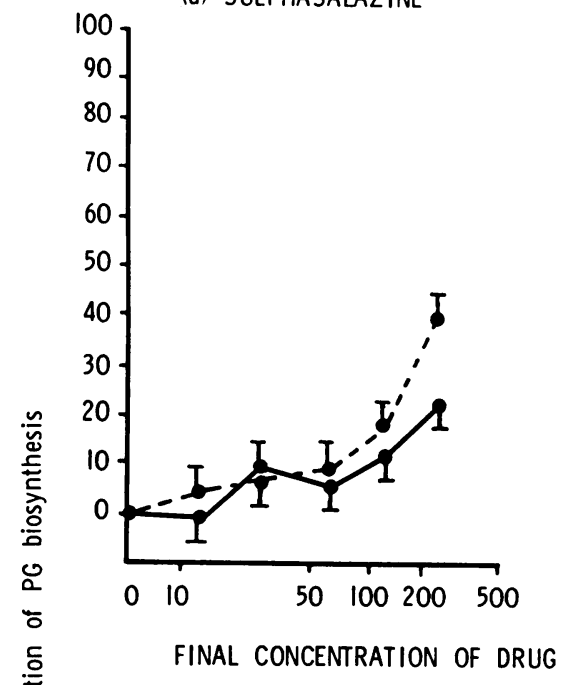

(c) PREDNISOLONE

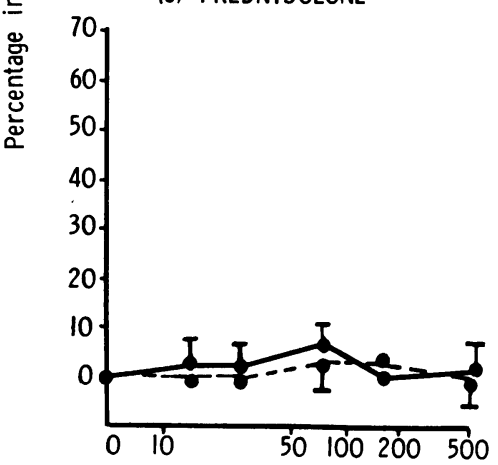

(b) INDOMETHACIN

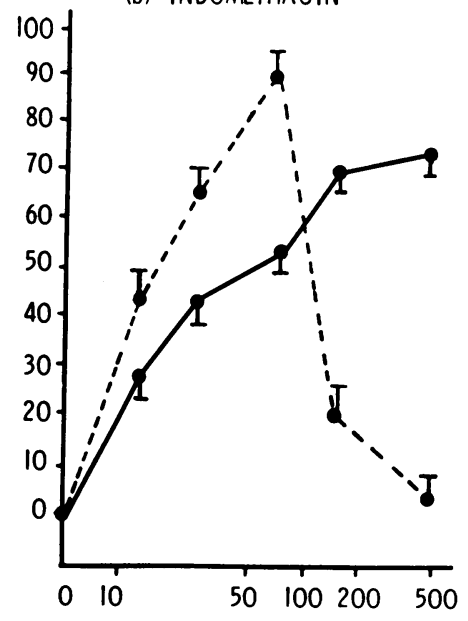

Fig. 2 Inhibition of prostaglandin biosynthesis by drugs in normal (--.-) and colitic (-) mucosal homogenates. Each point represents the mean value for four experiments.

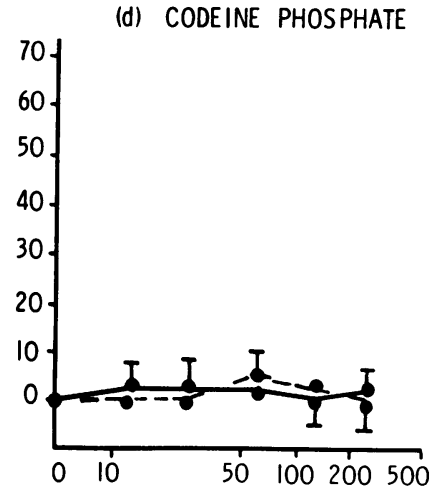

FINAL CONCENTRATION OF DRUG IN REACTION MIXTURE $\mu \mathrm{mO}$ ! /

fore be relevant in the in vivo situation. It is tempting to attribute the temporal fall in prostaglandin synthetase activity in the in vivo studies solely to the action of sulphasalazine. One must be cautious, however, as reduction in inflammation per se could be partially responsible.

In contrast with sulphasalazine, prednisolone and codeine phosphate produced no significant inhibition of prostaglandin synthetase in our system. Early reports suggested that steroids inhibited prostaglandin release in some tissues (Greaves et al., 1973 Tashjian et al., 1975), while in other tissues little or no inhibition was shown (Flower et al., 1972). Lewis and Piper (1975) explain the effect of steroids as an inhibition of prostaglandin release due to a membrane stabilising effect, rather than an inhibition of synthesis. The effects of codeine phosphate on prostaglandin production have not been widely investigated. Collier et al., (1976b) in a study of drugs stimulating prostaglandin biosynthesis found that codeine phosphate was not stimulatory even at high concentrations.

Ingested sulphasalazine is split by colonic bacterial action to release free sulphapyridine and 5-aminosalicylic acid (5-ASA) (Svartz et al., 1945). Gould (1975) showed that the 5-ASA moiety of sulphasalazine was as potent as the intact parent compound in inhibiting tone in the rat fundic strip, although Collier et al. (1976a) found 5-ASA to be less effective than sulphasalazine in inhibiting prostaglandin biosynthesis in bovine seminal vesicle preparations. Azad Khan et al. (1977) have shown that the clinical benefit of 5-ASA administered as enemata to patients with ulcerative colitis was similar to that 
obtained with sulphasalazine enemata.

It is difficult to conceive that an increased prostaglandin synthetase activity has a primary role in the aetiology of ulcerative colitis; it seems more likely to be a result of the inflammatory disorder. This is supported by our finding that the percentage inhibition of prostaglandin biosynthesis produced by indomethacin and sulphasalazine is similar for both normal and colitic mucosae, although the absolute activities differ. It is probable that mucosal damage in ulcerative colitis leads to lysosomal rupture and activation of phospholipase $A$, the rate-limiting step in the pathway leading to PG biosynthesis. The site of production of prostaglandins within the mucosa is unknown but mitogen and antigen-stimulated lymphocytes have been shown to produce them in culture (Ferraris and De Rubertis, 1974) and their presence in the inflammatory infiltrate in ulcerative colitis suggests a possible site of prostaglandin biosynthesis.

Although we have shown inhibition in vitro of prostaglandin synthetase activity by sulphasalazine, the inhibition produced by indomethacin was greater. The finding that indomethacin was less inhibitory at high concentrations is surprising. However, Bennet (1973) has observed a similar effect of benorylate upon prostaglandin biosynthesis in human gut tissue. Indomethacin, aspirin, and other non-steroidal anti-inflammatory agents are proven inhibitors of prostaglandin synthetase (Vane, 1971; 1976). Prostaglandin synthetase inhibitors have been used successfully in the treatment of food intolerance allergies (Buisseret et al., 1978), while Mennie et al. (1975) have used aspirin in the treatment of radiation induced colitis resistant to standard forms of therapy. A therapeutic role for such inhibitors of prostaglandin synthetase activity in ulcerative colitis should be investigated.

\section{References}

Azad Kahn, A. K., Piris, J., and Truelove, S. C. (1977). An experiment to determine the active therapeutic moiety of sulphasalazine. Lancet, 2, 892-895.

Bennett, A., Fox, C. F., and Stamford, I. F. (1973). Inhibition of prostaglandin synthesis by benorylate. Rheumatology and Rehabilitation suppl, 101-105.

Buisseret, P. D., Youlten, L. J., Heinzelmann, D. I., and Lessof, M. H. (1978). Prostaglandin-synthesis inhibitors in prophylaxis of food intolerance. Lancet, 1, 906-908.

Collier, H. O. J., Francis, A. A., McDonald-Gibson, W. J., and Saeed, S. A. (1976a). Inhibition of prostaglandin biosynthesis by sulphasalazine and its metabolites. Prostaglandins, 11, 219-225

Collier, H. O. J., McDonald-Gibson, W. J., and Saeed, S. A. (1976b). Stimulation of prostaglandin biosynthesis by drugs: effects in vitro of some drugs affecting gut function. British Journal of Pharmacy, 58, 193-199.
Cummings, J. H., Milton-Thompson, G. J., Billings, J. A., Newman, A., and Misiewicz, J. J. (1972). The effect of intravenous prostaglandin $F_{2}$ in small intestinal function. Gut, 13, 854.

Das, K. M., Eastwood, M. A., McManus, J. P. A., and Sircus, W. (1973). The metabolism of salicylazosulphapyridine in ulcerative colitis. Gut, 14, 631-641.

Ferraris, V. A., and DeRubertis, F. R. (1974). Release of prostaglandins by mitogen - and antigen - stimulated leukocytes in culture. Journal of Clinical Investigation, 54, 378-386.

Flower, R., Cryglewski, R., Herbaczynska-Cedro, K., and Vane, J. R. (1972. Effects of anti-inflammatory drugs on prostaglandin biosynthesis. Nature (New Biol.), 238, 104-106.

Gould, S. R. (1975). Prostaglandins, ulcerative colitis and sulphasalazine. Lancet, $2,988$.

Gould, S. R., Brash, A. R., and Conolly, M. E. (1977). Increased prostaglandin production in ulcerative colitis. Lancet, $2,98$.

Greaves, M. W., and McDonald-Gibson, W. J. (1973). Effects of non-steroid anti-inflammatory drugs on prostaglandin biosynthesis by skin. British Journal of Dermatology, 88, 47-50.

Green, K., and Samuelsson, B. (1964). Thin layer chromatography of prostaglandins. Journal of Lipid Research, 2, 117-120.

Harris, D. W., Smith, P. R., and Swan, C. H. J. (1978a). Determination of prostaglandin synthetase activity in rectal biopsy material and its significance in colonic disease. Gut, 19, 875-877.

Harris, D. W., Smith, P. R., and Swan, C. H. J. (1978b). Venous prostaglandin-like activity in diarrhoeal states. Gut, 19, 1057-1058.

Horton, E. W., Main, I. H. M., Thompson, C. J., and Wright, P. M. (1968). Effects of orally administered prostaglandin $E_{1}$ on gastric secretion and gastrointestinal motility in man. Gut, 9, 655-658.

Lewis, G. P., and Piper, P. J. (1975). Inhibition of release of prostaglandins as an explanation of some of the actions of anti-inflammatory corticosteroids. Nature, 254, 308-311.

Mennie, A. T., Dalley, V. M., Dineen, L. C., and Collier H. O. J. (1975). Treatment of radiation-induced gastrointestinal distress with acetylsalicylate. Lancet, 2, 942-943.

Misiewicz, J. J., Waller, S. L., Kiley, N., and Horton, E. W. (1969). Effect of oral prostaglandin $E_{1}$ on intestinal transit in man. Lancet, 1, 648-651.

Sandler, M., Karim, S. M. M., and Williams, E. D. (1968). Prostaglandins in amine-peptide-secreting tumours. Lancet, 2, 1053-1054.

Svartz, N., Kallner, S., and Helander, S. (1945). Sonderdelas salazopyrin snabbt in organismen? Nordisk Medicin, 25, 211-212.

Tashjian, A. H., Veobel, E. F., McDonough, J., and Levine, L. (1975). Hydrocortisone inhibits prostaglandin production by mouse fibrosarcoma cells. Nature, 258, 739-741.

Vane, J. R. (1971). Inhibition of prostaglandin synthesis as a mechanism of action for asprin-like drugs. Nature (New Biol.), 231, 232.

Vane, J. R. (1976). The mode of action of aspirin and similar compounds Journal of Allergy and Clinical Immunology, 58, 691-712.

Williams, E. D., Karim, S. M. M., and Sandler, M. (1968). Prostaglandin secretion by medullary carcinoma of the thyroid. Lancet, 1, 22.

Waller, S. L. (1973). Prostaglandins and the gastrointestinal tract. Gut, 14, 402-417. 